\title{
Study of Monoethanolamine Nitrate Content Reduction in Explosive Slurries
}

Fábrica Presidente Vargas 12620-000 Piquete, SP, Brazil

\section{J. A. Carvalho Jr.}

\author{
J. N. C. Castro \\ Universidade Estadual Paulista - UNESP \\ Faculdade de Engenharia de Guaratinguetá \\ Departamento de Energia \\ 12516-410 Guaratinguetá, SP, Brazil
}

\section{Bastos-Netto}

Instituto Nacional de Pesquisas Espaciais - INPE Lab. Associado de Combustão e Propulsão 12630-000 Cachoeira Paulista, SP, Brazil
The reduction of the fuel content of a monoethanolamine nitrate (MEAN) fueled explosive slurry was investigated. The work was performed in three phases. The first one involved the MEAN content reduction in a reference slurry from its initial value of 36 down to $24 \%$ by weight, the balance being filled with ammonium nitrate, the least expensive item in the slurry composition. This proved to be successful, leading to an overall cost reduction of 17\%, while keeping the overall performance quite satisfactory. The second phase consisted in trying to bring the MEAN content down from 24 to 17\%. Although this led to further cost reduction, the formulations, obtained by substituting part of the MEAN content by ammonium nitrate/fuel oil (ANFO), produced unsatisfactory results regarding ignition and densities. In the third phase, the Design of Experiments Technique was used to find formulations displaying not only lower cost, but also acceptable overall performance. This led to a raw material cost reduction ranging from 23 to $26 \%$ relative to the initial reference slurry formulation.

Keywords: explosive slurries, monoethanolamine nitrate (MEAN), explosive cost and performance

\section{Introduction}

Following Nobel's dynamite and the blasting gelatin developments which took over from the black powder its monopoly in mining and demolitions up to late Nineteenth Century, a lot of different chemicals have been tried for civilian applications. Common to all explosives is their heterogeneous structure, the great work capacity (blast effect) and the advantage that the detonation releases small amounts of poisonous gases (Ringgenberg and Mathieu, 2004). Parameters for characterization of an explosive are, among others, heat of explosion (Pepekin and Gubin, 2007), detonation velocity (Wharton et al., 2000), strength (Afanasenkov et al., 2001), and thermal stability (Krabbendam-LaHaye et al., 2005).

In the Fifties a new generation of explosives, the slurries, was developed by Cook and Farnam (1960). They basically consisted of a mixture of oxidizing salts, a sensitizing solid fuel mixture and water, plus a thickener (such as guar gum or an alginate) (Cooper, 1996; Berta, 1990; Urbanski, 1990; Meyer, 1987). The best known slurry product has been E.I. duPont de Nemour's Tovex ${ }^{\circledR}$ (Berta, 1990; Urbanski, 1990; Meyer, 1987), which made use of monomethilamine nitrate (MMAN) as fuel agent.

It is well known that explosive slurries, fueled with MMAN or with monoethanolamine nitrate (MEAN) are widely employed nowadays thanks to their performance, safe processing and handling, plus a good water resistance, so that they are still able to share the world market with the more recent fourth generation explosives such as the explosive emulsions (which consist basically of ammonium nitrate solution droplets protected by a solid fuel matrix).

The most expensive item of a modern slurry is its fuel. In a slurry with MEAN, this accounts for $70 \%$ of the overall components cost. Therefore, it is important to look into the possibility of substituting part of the slurry MEAN content by a combination of less expensive items (such as diesel fuel, iron oxide, mineral oil, waxes, sulfur, etc).

This led to the present work, which specifically deals with MEAN fueled slurries investigating the substitution of part their MEAN content by a less expensive item and its implications in

Paper accepted October, 2009. Technical Editor: Celso Kazuyuki Morooka safety, performance, storage and overall cost. This was done using as reference the slurry formulation processed in Brazil by Presidente Vargas Plant, Piquete, State of São Paulo.

\section{Reference Slurry Main Constituents, its Properties, Processing Technique and Ballistic Test Description}

The slurry used as reference in this work was composed of monoethanolamine nitrate (MEAN) as the main component, with a concentration of $86 \%$ by weight, ammonium nitrate as the primary oxygen source, and sodium and calcium nitrates as alternate oxygen sources. Both the sodium and calcium nitrates are responsible for the slurry low temperature properties and performance, the former being responsible for its storage properties, and the latter being added only in those batches with a $\mathrm{pH}$ lower than 6.0 , when it behaves as a cross-linking agent, besides allowing the production of slurries with higher density and sensitivity. The slurry composition is completed with water to hydrate the thickener agent (in this case guar gum), rubber powder (a mixture consisting of $75 \%$ butadiene and $25 \%$ styrene) for oxygen balance adjustments, potassium pyroantimmoniate (PPA) as the cross linking agent, iron oxide ("blue dust", to increase the explosive density and sensitivity, generating "hot points"), and sulfur (which, besides being a fuel, increases the slurry sensitivity). The reference slurry component properties are shown in Table 1.

The slurry was prepared in batches and its preparation technique followed four phases: 1) conditioning of the constituents, 2) liquor preparation, 3) mixing, and 4) casing (cartridge loading). Each batch consisted, on the overage, of $5 \mathrm{~kg}$ of finished product. Figure 1 depicts the processing technique flowchart.

The slurry casing (cartridges) consisted of tubular polyethylene films of 32 or $51 \mathrm{~mm}$ diameter and $406 \mathrm{~mm}$ length, closed at both ends with aluminum clips, giving them a sausage like appearance. Ballistic tests took place at least 48 hours after the loading phase. The ballistic tests performed were the well known Trauzl lead block tests and the digital counter for detonation velocity measurements.

\section{Experiment Description}

The experimental work was performed in three phases. In the first phase, the slurry MEAN content was reduced from its initial 
value of 36 to $24 \%$ (by weight), this difference being compensated by the equivalent addition of ammonium nitrate (AN). This approach was deemed acceptable, because both of them are in the fuel class consisting in the most (MEAN) and the least (AN) expensive items in the slurry composition, respectively.

Table 1. Reference slurry components properties.

\begin{tabular}{llll}
\hline Component & $\begin{array}{l}\text { Molecular } \\
\text { Weight, g/mol }\end{array}$ & $\begin{array}{l}\text { Enthalpy of } \\
\text { Formation, Cal/g }\end{array}$ & $\begin{array}{l}\text { Fusion } \\
\text { Temperature, }{ }^{\circ} \mathrm{C}\end{array}$ \\
\hline MEAN & 124.1 & -1362.1 & 10.5 \\
Ammonium nitrate & 80 & -1092 & 169.6 \\
Sodium nitrate & 85 & -1312 & 306.8 \\
Calcium nitrate & 164 & -1717 & 561 \\
Guar gum & 220000 & -1648 & - \\
Water & 18 & -3795 & - \\
Undensifier & 3759.1 & -300 & - \\
Rubber powder & 150.27 & -2800 & - \\
Iron oxide & 160 & 1231 & - \\
PPA & 2555.4 & -2317 & - \\
Sulfur & 32 & 0 & - \\
\hline
\end{tabular}

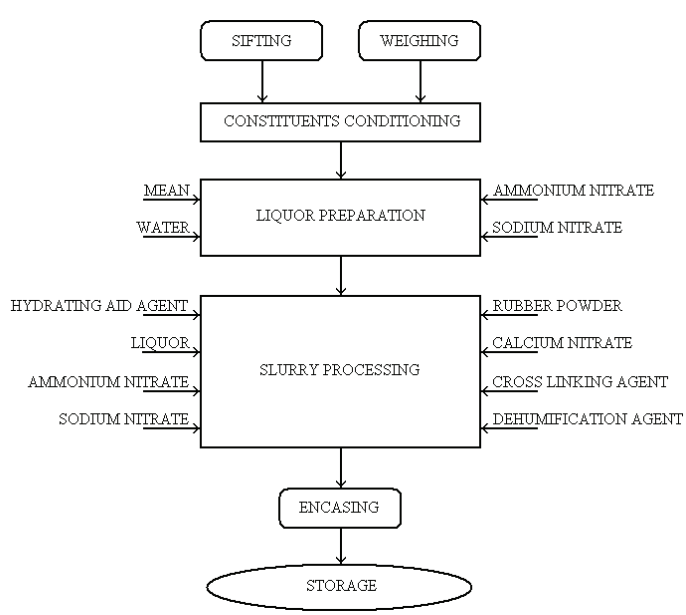

Figure 1. Slurry processing technique flowchart.

The second phase consisted in trying to bring the MEAN content down to $17 \%$. Although this allowed a strong cost reduction as compared to the reference slurry, these formulations displayed problems with ignition, and some sensitivity to the NP10 detonation cord and to the \#8 blasting cap, besides exhibiting densities below $1.0 \mathrm{~g} / \mathrm{cm}^{3}$ (the desired values being larger than $1.1 \mathrm{~g} / \mathrm{cm}^{3}$ ).

The results of phase two led to a third phase in which the Design of Experiments Technique (Roy, 2001) was used. The technique was used to attempt reduction of manufacturing costs without deteriorating the explosive performance.

In each phase calculations were needed in order to obtain the characteristics of a new formulation before processing it in practice. This was done using an in house code labeled CALCEXPLO (Roux, 1990). Another computer program that predicts parameters of confined charges is that reported by Rigas et al. (1994).

\section{Results and Discussion}

\section{Phase 1 - MEAN Content Reduction from 36 to $24 \%$}

In this phase the idea was not to change the original formulation too drastically. This decision was taken based on the oxygen balance (OB) of the reference slurry, which is nearly $-4 \%$ (it is desired +1 $\%$ for this type of explosive, i.e., a slightly positive value). Figure 2 shows the evolution of the overall OB with the MEAN content reduction. Obviously, these values could easily be modified by changing the contents of other constituents such as rubber powder or sodium nitrate.

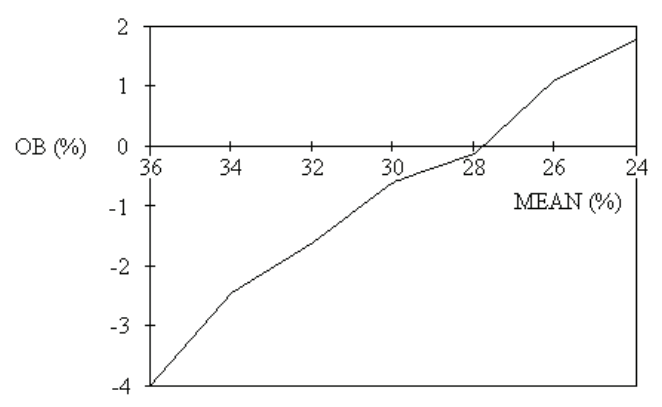

Figure 2. Oxygen balance as function of the MEAN content.

Another important step was the complete withdrawal of the calcium nitrate $\left(\mathrm{Ca}\left(\mathrm{NO}_{3}\right)_{2}\right)$ in the formulation with $24 \%$ MEAN. This procedure, based on theoretical calculations, led to expressive improvements in the heat of detonation and in the relative strength, as shown in Table 2 .

The expected cost with the new laboratory tested formulations of phase one is shown in Table 3, while Tables 4 and 5 show the theoretical and experimental results obtained with the gradual reduction of the MEAN content in samples ranging from the content in the reference slurry of $36 \%$ (S36) down to $24 \%$ (D24), in $2 \%$ wide steps.

It can be seen from Table 5 that all formulations performed reasonably well. It is worth to notice that the MEAN content reduction from 36 to $24 \% \mathrm{wt}$. led to a $17 \%$ cost reduction, as shown in Table 3.

This slurry composition is receiving good acceptance in the Brazilian market thanks to its performance and competitive price even if compared with the more recent explosive emulsions.

\section{Phase 2 - MEAN Content Reduction Down to 17\% wt}

This phase consisted in trying to find formulations leading to an overall constituent cost reduction ranging from 20 to $30 \%$ as compared to the standard slurry composition. Several formulations were tried and their results (both theoretical and experimental) are shown in Tables 6 to 8. Formulation D20 was intended to yield a hybrid explosive through the mixing of slurry and ANFO. This was done following all steps of the standard fabrication plan and it led to a low sensitivity of the explosive which responded to the \#8 blasting cap only.

Table 2. Theoretical results for $24 \%$ MEAN content with and without calcium nitrate.

\begin{tabular}{|c|c|c|c|c|c|}
\hline Type of slurry & $\begin{array}{l}\text { Reference } \\
\text { slurry }\end{array}$ & $\begin{array}{l}24 \% \mathrm{MEAN} \\
\text { in } \mathrm{Ca}\left(\mathrm{NO}_{3}\right)_{2}\end{array}$ & Difference & $\begin{array}{l}24 \% \mathrm{MEAN} \\
\text { with } \mathrm{Ca}\left(\mathrm{NO}_{3}\right)_{2}\end{array}$ & Difference \\
\hline Heat of detonation, cal $/ \mathrm{g}$ & 788 & 786 & $0.25 \%$ & 690 & $12.44 \%$ \\
\hline Relative strength, $\%$ & 61 & 60 & 1.64 & 53 & $13.12 \%$ \\
\hline
\end{tabular}


Table 3. Product cost (materials only) in formulations with gradual reduction of MEAN content from reference value down to $24 \%$ wt.

\begin{tabular}{lllllllll}
\hline Raw Materials & US\$/kg* & D36 (Ref.) & D34 & D32 & D30 & D28 & D26 & D24 \\
\hline MEAN, \% & 1.32 & 36.02 & 33.99 & 31.97 & 30.01 & 28.02 & 26.04 & 24.16 \\
$\mathrm{NH}_{4} \mathrm{NO}_{3}, \%$ & 0.30 & 36.94 & 38.91 & 40.94 & 42.89 & 45.12 & 47.75 & 54.09 \\
$\mathrm{NaNO}_{3}, \%$ & 0.41 & 9.53 & 9.60 & 9.13 & 9.52 & 9.91 & 9.99 & 14.75 \\
Water, \% & 0.00 & 2.84 & 3.03 & 3.22 & 3.36 & 3.85 & 3.89 & 3.82 \\
$\mathrm{Ca}\left(\mathrm{NO}_{3}\right)_{2}, \%$ & 0.31 & 11.78 & 11.72 & 11.82 & 11.20 & 9.91 & 8.88 & 0.00 \\
Guar gum, \% & 3.30 & 0.95 & 0.91 & 0.97 & 1.01 & 0.99 & 1.00 & 0.98 \\
Rubber powder, \% & 0.40 & 1.07 & 1.01 & 1.08 & 1.12 & 1.32 & 1.56 & 1.31 \\
Undensifiers, \% & 1.59 & 0.87 & 0.83 & 0.87 & 0.89 & 0.88 & 0.89 & 0.89 \\
Cost* (US\$/kg) & & 0.71 & 0.69 & 0.67 & 0.65 & 0.63 & 0.61 & 0.59 \\
\hline
\end{tabular}

*Values may vary according to the exchange rate between the dollar and the Brazilian currency, the Real.

Table 4. Theoretical performance in formulations with gradual reduction of MEAN content from the reference value down to $24 \%$ wt.

\begin{tabular}{llllllll}
\hline Characteristics & \multicolumn{7}{c}{ Formulation } \\
\cline { 2 - 8 } & D36, (Ref.) & D34 & D32 & D30 & D28 & D26 & D24 \\
\hline Oxygen balance, \% & -4.02 & -2.43 & -1.56 & -0.58 & -0.09 & 0.31 & 2.42 \\
Gaseous sp. volume, liter/kg & 890 & 880 & 878 & 871 & 870 & 872 & 864 \\
Heat of detonation, cal/g & 788 & 808 & 814 & 826 & 826 & 811 & 759 \\
Relative strength, \% & 0.61 & 0.62 & 0.62 & 0.63 & 0.63 & 0.62 & 0.58 \\
Lead block, cm ${ }^{3}$ & 301 & 305 & 306 & 308 & 308 & 305 & 284 \\
Detonation velocity, m/s & 3997 & 4051 & 4074 & 4107 & 4111 & 4090 & 3995 \\
\hline
\end{tabular}

Table 5. Experimental results obtained by gradually decreasing the MEAN content from reference value down to $24 \%$ wt.

\begin{tabular}{|c|c|c|c|c|c|c|c|}
\hline \multirow[t]{2}{*}{ Characteristics } & \multicolumn{7}{|c|}{ Formulation } \\
\hline & D36 (Ref.) & D34 & D32 & D30 & D28 & D26 & D24 \\
\hline Lead block, $\mathrm{cm}^{3}$ & 302 & 325 & 268 & 270 & 280 & 275 & 297 \\
\hline Detonation velocity*, $\mathrm{m} / \mathrm{s}$ & 4000 & 4835 & 4301 & 4554 & 4325 & 4120 & 4050 \\
\hline Bulk density, $\mathrm{g} / \mathrm{cm}^{3}$ & 1.10 & 1.10 & 1.10 & 1.10 & 1.10 & 1.10 & 1.15 \\
\hline Sensitivity (\# 8 blasting cap) & Yes & Yes & Yes & Yes & Yes & Yes & Yes \\
\hline Sensitivity (NP10 explosive cord) & Yes & Yes & Yes & Yes & Yes & Yes & Yes \\
\hline
\end{tabular}

Table 6. Costs through MEAN content reduction down to $17 \%$ wt.

\begin{tabular}{llllllllll}
\hline Raw Materials & \multicolumn{10}{c}{ Formulation } \\
\cline { 2 - 10 } & D20 & D20a & D20b & D20c & D20d & D20e & D18 & D18a & D18b \\
\hline MEAN, \% & 19.88 & 19.96 & 19.56 & 19.00 & 19.99 & 20.01 & 16.99 & 16.96 & 16.99 \\
Ammonium nitrate, \% & 60.39 & 56.81 & 61.18 & 59.94 & 56.91 & 56.97 & 63.22 & 63.29 & 63.38 \\
Sodium nitrate, \% & 12.07 & 13.90 & 11.68 & 13.24 & 13.92 & 13.94 & 11.84 & 11.81 & 11.83 \\
Water, \% & 2.47 & 4.96 & 4.87 & 4.73 & 4.97 & 4.98 & 4.73 & 4.73 & 4.73 \\
Calcium nitrate, \% & 0.00 & 0.00 & 0.00 & 0.00 & 0.00 & 0.00 & 0.00 & 0.00 & 0.00 \\
Guar gum, \% & 0.99 & 0.99 & 0.97 & 0.95 & 0.99 & 1.00 & 0.85 & 0.84 & 0.85 \\
Rubber powder, \% & 0.99 & 0.99 & 0.97 & 1.89 & 0.99 & 1.00 & 1.69 & 1.69 & 1.69 \\
Diesel oil, \% & 1.48 & 1.18 & 0.00 & 0.00 & 1.19 & 1.19 & 0.00 & 0.00 & 0.00 \\
Undensifier agent, \% & 1.73 & 1.21 & 0.77 & 0.25 & 1.04 & 0.91 & 0.68 & 0.68 & 0.53 \\
Cost*, US\$/kg & 0.47 & 0.48 & 0.54 & 0.53 & 0.48 & 0.48 & 0.47 & 0.47 & 0.47 \\
\hline
\end{tabular}

*Values may vary according to the exchange rate between the dollar and the Brazilian currency, the Real.

Table 7. Comparison of theoretical results between reference values and phase two formulations.

\begin{tabular}{|c|c|c|c|c|c|c|c|c|c|c|}
\hline \multirow[t]{2}{*}{ Characteristics } & \multicolumn{10}{|c|}{ Formulation } \\
\hline & D36 (Ref.) & D20 & D20a & D20b & D20c & D20d & D20e & D18 & D18a & $\mathrm{D} 18 \mathrm{~b}$ \\
\hline Oxygen balance, $\%$ & -4.02 & -0.59 & 0.59 & 4.77 & 3.42 & 0.92 & 0.59 & 4.69 & 4.72 & 4.73 \\
\hline Gaseous specific volume, liter/kg & 890 & 895 & 885 & 901 & 884 & 885 & 885 & 895 & 896 & 895 \\
\hline Heat of detonation, cal/g & 788 & 855 & 824 & 664 & 700 & 810 & 827 & 650 & 649 & 650 \\
\hline Relative strength, $\%$ & 0.61 & 0.65 & 0.63 & 0.53 & 0.55 & 0.62 & 0.63 & 0.52 & 0.52 & 0.52 \\
\hline Lead block, $\mathrm{cm}^{3}$ & 301 & 317 & 309 & 244 & 259 & 306 & 310 & 236 & 236 & 236 \\
\hline Detonation velocity, $\mathrm{m} / \mathrm{s}$ & 3997 & 4112 & 4070 & 3831 & 3904 & 4050 & 4076 & 3818 & 3817 & 3819 \\
\hline
\end{tabular}

Table 8. Experimental results, phase two formulations.

\begin{tabular}{|c|c|c|c|c|c|c|c|c|c|c|}
\hline \multirow[t]{2}{*}{ Characteristics } & \multicolumn{10}{|c|}{ Formulation } \\
\hline & D36 (Ref.) & D20 & D20a & D20b & D20c & D20d & D20e & D18 & D18a & D18b \\
\hline Lead block, $\mathrm{cm}^{3}$ & 302 & 252 & - & 309 & 261 & - & - & 250 & 235 & 246 \\
\hline Detonation velocity*, $\mathrm{m} / \mathrm{s}$ & 4000 & - & - & 2883 & 2941 & - & - & 2752 & 2672 & 2688 \\
\hline Bulk density, $\mathrm{g} / \mathrm{cm}^{3}$ & 1.10 & 1.22 & 1.24 & 0.85 & 1.08 & 1.22 & 1.24 & 0.87 & 0.90 & 0.90 \\
\hline Sensitivity (\# 8 blasting cap) & Yes & Yes & No & Yes & Yes & No & No & Yes & Yes & Yes \\
\hline Sensitivity (NP10 explosive cord) & Yes & No & No & Yes & No & No & No & Yes & Yes & Yes \\
\hline
\end{tabular}


Formulation D20a consisted in modifying the ANFO addition sequence only, the results being even worse because the explosive was shown to be insensitive to both the \#8 fuse and the detonation cord. Formulation D20c did not contain ANFO and it displayed good results for the lead block readings, the detonation velocity and the sensitivity. However, its bulk density was deemed too low. Formulations D20d and D20e, in which ANFO was added after the last step of the slurry preparation, ran into the same problems of formulations D20 and D20a. Finally, formulations D18, D18a and D18b, which consisted in formulation D24 with its MEAN content reduced to $17 \%$, showed again unsatisfactory results, with a very low bulk density reading.

\section{Phase 3 - Use of the Design of Experiments Technique}

As first step of this procedure a list was made of every possible option which could lead eventually to the desired improvement. From a broad range of possibilities, which included 25 options, a thorough analysis was performed and 3 items were selected: TNT, $\mathrm{Fe}_{3} \mathrm{O}_{4}$ and $\mathrm{S}$. As iron oxide and sulfur had already been used in similar formulations, compatibility tests were performed with TNT and slurry to clear safety aspects of fabrication and of storage. The maximum amount of each one of these components was next established through investigation of existing conventional compositions. This consisted of approximately $2.0 \% \mathrm{wt}$. for both iron oxide and sulfur. Then, a composition was set up based upon formulation D22c which would be $98 \%$ wt. of the total batch, the remaining $2 \%$ being split among the three chosen options. Then, $\mathrm{C}_{\mathrm{i}}$ was the weight concentration of species $\mathrm{i}$, ( $\mathrm{i}=\mathrm{TNT}, \mathrm{Fe}_{3} \mathrm{O}_{4}$ and $\left.\mathrm{S}\right)$, and, similarly, $\mathrm{C}_{\mathrm{D} 22 \mathrm{c}}=98 \%$. Holding the amount of formulation D22c constant, three formulations could then be created. Considering only the variable terms, their geometric representation takes the form of Figure 3, for which the vertices are $(2,0,0),(0,2,0)$ and $(0,0,2)$.

Next, as the knowledge of the effects caused by these materials was still not known, three more formulations were chosen, midway the sides of the triangle, i.e., $(1,1,0),(1,0,1)$ and $(0,1,1)$, respectively. Finally a seventh formulation was chosen, corresponding to the center of the triangle, i.e., $(2 / 3,2 / 3,2 / 3)$. This way the matrix of formulations was built as shown in Table 9 .

Table 10 shows the theoretical results from each formulation and compares them with the reference composition (D36). Notice that formulation PE2 alone yielded a low value for the heat of detonation compared to the value of the reference composition. Even so, it seemed convenient to run a test with that formulation in order to better evaluate the influence of the iron oxide in the explosive sensitivity. Results of 52 trials during this phase can be found in Tables 11 and 12, the latter presenting them as averaged values.

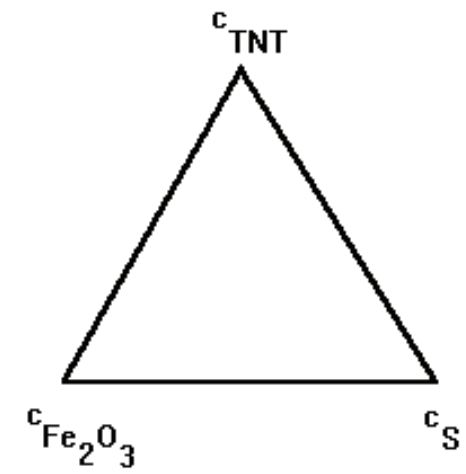

Figure 3. Geometric representation of modifying species used in the new composition.

A first analysis indicated that formulation PE1 did not show good results concerning its sensitivity. Also, it was quite difficult to obtain bulk density values close to the desired ones. On the other hand, formulation PE2, which, in theory, could be expected not to show good results, performed quite well, showing also the influence of the iron oxide in improving the explosive sensitivity.

\section{Analysis of the Statistical Model}

The matrix of formulation was set up assuming a fixed constant part and a variable one, the latter consisting of three factors, namely, TNT, iron oxide and sulfur. The cubic model adopted allowed these factors to be treated as pseudo components of a mixture so that their upper limits could be represented as standard percentages, i.e., $0 \% \leq$ $\mathrm{x}_{\mathrm{i}} \leq 100 \%$, where $\mathrm{i}=1,2,3$ for TNT, $\mathrm{Fe}_{2} \mathrm{O}_{3}$ and $\mathrm{S}$, respectively.

Table 9. Matrix of formulations, phase three.

\begin{tabular}{|c|c|c|c|c|c|c|c|c|}
\hline \multirow[b]{2}{*}{ Component } & \multicolumn{8}{|c|}{ Formulation } \\
\hline & D36 (Ref.) & PE1 & PE2 & PE3 & PE4 & PE5 & PE6 & PE7 \\
\hline MEAN, \% & 36.02 & 19.04 & 19.04 & 19.04 & 19.04 & 19.04 & 19.04 & 19.04 \\
\hline Ammonium nitrate, $\%$ & 36.94 & 61.92 & 61.92 & 61.92 & 61.92 & 61.92 & 61.92 & 61.92 \\
\hline Sodium nitrate, $\%$ & 9.53 & 11.77 & 11.77 & 11.77 & 11.77 & 11.77 & 11.77 & 11.77 \\
\hline Water, \% & 2.84 & 2.84 & 2.84 & 2.84 & 2.84 & 2.84 & 2.84 & 2.84 \\
\hline Calcium nitrate, $\%$ & 11.78 & 0.00 & 0.00 & 0.00 & 0.00 & 0.00 & 0.00 & 0.00 \\
\hline Guar gum, $\%$ & 0.95 & 0.81 & 0.81 & 0.81 & 0.81 & 0.81 & 0.81 & 0.81 \\
\hline Rubber powder, $\%$ & 1.07 & 1.32 & 1.32 & 1.32 & 1.32 & 1.32 & 1.32 & 1.32 \\
\hline TNT, $\%$ & 0.00 & 2.03 & 0.00 & 0.00 & 1.02 & 1.02 & 0.00 & 0.71 \\
\hline Iron oxide, \% & 0.00 & 0.00 & 2.03 & 0.00 & 1.02 & 0.00 & 1.02 & 0.71 \\
\hline Sulfur & 0.00 & 0.00 & 0.00 & 2.03 & 0.00 & 1.02 & 1.02 & 0.71 \\
\hline Undensifier agent, \% & 0.87 & 0.27 & 0.27 & 0.27 & 0.26 & 0.26 & 0.26 & 0.17 \\
\hline Cost*, US\$/kg & 0.71 & 0.55 & 0.52 & 0.53 & 0.54 & 0.54 & 0.53 & 0.53 \\
\hline
\end{tabular}

*Values may vary according to the exchange rate between the dollar and the Brazilian currency, the Real. 
Table 10. Theoretical results.

\begin{tabular}{lllllll}
\hline \multicolumn{7}{c}{ Calculated Results } \\
\hline Composition & $\begin{array}{l}\text { VOD, } \\
\mathrm{m} / \mathrm{s}\end{array}$ & $\begin{array}{l}\text { Heat of detonation, } \\
\mathrm{cal} / \mathrm{g}\end{array}$ & $\begin{array}{l}\text { Gaseous specific } \\
\text { volume, } \mathrm{l} / \mathrm{kg}\end{array}$ & $\begin{array}{l}\text { Relative } \\
\text { strength, } \\
\%\end{array}$ & $\begin{array}{l}\text { Cost, } \\
\text { US\$/kg }\end{array}$ & $\begin{array}{l}\text { Difference, } \\
\%\end{array}$ \\
\hline D36 (Ref.) & 3997 & 788 & 890 & 60 & 0.71 & - \\
D24 & 3995 & 786 & 874 & 60 & 0.64 & 10 \\
PE1 & 3977 & 745 & 885 & 58 & 0.55 & 23 \\
PE2 & 3853 & 654 & 873 & 52 & 0.52 & 26 \\
PE3 & 4065 & 789 & 866 & 60 & 0.53 & 25 \\
PE5 & 4022 & 769 & 876 & 59 & 0.54 & 24 \\
PE6 & 3964 & 723 & 870 & 56 & 0.53 & 25 \\
PE7 & 3974 & 734 & 874 & 57 & 0.53 & 25 \\
\hline
\end{tabular}

Table 11. Ballistic results, individual samples.

\begin{tabular}{|c|c|c|c|c|c|c|c|}
\hline Formulation & $\begin{array}{l}\text { Sample } \\
\text { number }\end{array}$ & $\begin{array}{l}\text { Bulk } \\
\text { Density, } \\
\mathrm{g} / \mathrm{cm}^{3}\end{array}$ & $\begin{array}{l}\text { VOD, } \\
\mathrm{m} / \mathrm{s}\end{array}$ & $\begin{array}{l}\text { Lead block, } \\
\mathrm{cm}\end{array}$ & $\begin{array}{l}\text { Booster } \\
\text { PV15 }\end{array}$ & $\begin{array}{l}\text { Blasting cap } \\
\# 8\end{array}$ & $\begin{array}{l}\text { Explosive cord } \\
\text { NP10 }\end{array}$ \\
\hline \multirow{3}{*}{$\begin{array}{l}\text { PE1A } \\
\\
\\
\text { TNT }\end{array}$} & 1 & 1.22 & - & - & No & No & No \\
\hline & 2 & 1.24 & - & - & No & No & No \\
\hline & 3 & 1.24 & - & - & No & No & No \\
\hline \multirow{4}{*}{$\begin{array}{ll}\text { PE1B } & \\
& \text { TNT }\end{array}$} & 1 & 1.18 & 2956 & - & No & No & No \\
\hline & 2 & 1.20 & - & - & No & No & No \\
\hline & 3 & 1.21 & - & - & No & No & No \\
\hline & 4 & 1.21 & - & - & No & No & No \\
\hline \multirow[t]{5}{*}{ PE1C } & 1 & 1.14 & 3038 & - & - & Yes & No \\
\hline & 2 & 1.12 & 3085 & - & - & Yes & No \\
\hline & 3 & 1.11 & - & - & - & - & No \\
\hline & 4 & 1.15 & 3117 & - & Yes & - & No \\
\hline & 5 & - & - & 311 & - & - & - \\
\hline \multirow[t]{2}{*}{ PE2A } & 1 & 1.17 & 3438 & - & Yes & - & - \\
\hline & 2 & 1.15 & 3343 & - & - & - & Yes \\
\hline \multirow[t]{3}{*}{ Iron oxide } & 3 & 1.16 & 3352 & - & - & Yes & - \\
\hline & 4 & 1.15 & 3270 & - & - & - & Yes \\
\hline & 5 & 1.15 & - & 276 & - & - & - \\
\hline \multirow{5}{*}{$\begin{array}{l}\text { PE3A } \\
\text { Sulfur }\end{array}$} & 1 & 1.11 & 3132 & - & Yes & - & - \\
\hline & 2 & 1.10 & 3348 & - & - & Yes & - \\
\hline & 3 & 1.10 & 3212 & - & - & - & Yes \\
\hline & 4 & 1.09 & 3401 & - & - & - & Yes \\
\hline & 5 & 1.14 & - & 310 & - & - & - \\
\hline PE4A & 1 & 1.09 & 3333 & - & Yes & - & - \\
\hline TNT & 2 & 1.09 & 3513 & - & - & Yes & - \\
\hline \multirow[t]{3}{*}{ Iron oxide } & 3 & 1.08 & 3464 & - & - & - & Yes \\
\hline & 4 & 1.09 & 3326 & - & - & - & Yes \\
\hline & 5 & 1.11 & - & 280 & - & - & - \\
\hline \multirow{5}{*}{$\begin{array}{r}\text { PE5A } \\
\text { Sulfur } \\
\text { TNT }\end{array}$} & 1 & 1.15 & 3419 & - & Yes & - & - \\
\hline & 2 & 1.11 & 3438 & - & - & - & Yes \\
\hline & 3 & 1.15 & 3571 & - & - & Yes & - \\
\hline & 4 & 1.15 & 3297 & - & - & - & Yes \\
\hline & 5 & 1.12 & - & 289 & - & - & - \\
\hline \multirow{5}{*}{$\begin{array}{l}\text { PE6A } \\
\text { Sulfur } \\
\text { Iron oxide }\end{array}$} & 1 & 1.04 & 3252 & - & - & - & Yes \\
\hline & 2 & 1.06 & 3429 & - & - & - & Yes \\
\hline & 3 & 1.10 & 3529 & - & - & - & Yes \\
\hline & 4 & 1.09 & 3390 & - & - & - & Yes \\
\hline & 5 & - & - & 328 & - & - & - \\
\hline \multirow{5}{*}{$\begin{array}{l}\text { PE6B } \\
\text { Sulfur } \\
\text { Iron oxide }\end{array}$} & 1 & 1.10 & - & 282 & - & - & - \\
\hline & 2 & 1.15 & 3438 & - & - & - & Yes \\
\hline & 3 & 1.10 & 3125 & - & - & - & Yes \\
\hline & 4 & 1.13 & 3399 & - & - & - & Yes \\
\hline & 5 & 1.12 & 3429 & - & - & - & Yes \\
\hline PE7A & 1 & 1.03 & 3306 & - & - & - & Yes \\
\hline Sulfur & 2 & 1.03 & 3306 & - & - & - & Yes \\
\hline \multirow{3}{*}{$\begin{array}{r}\text { Iron oxide } \\
\mathrm{TNT}\end{array}$} & 3 & 1.01 & - & 304 & - & - & - \\
\hline & 4 & 1.05 & 3030 & - & - & - & Yes \\
\hline & 5 & 1.08 & 3352 & - & - & - & Yes \\
\hline \multirow{5}{*}{$\begin{array}{r}\text { PE7B } \\
\text { Sulfur } \\
\text { Iron oxide } \\
\text { TNT }\end{array}$} & 1 & 1.09 & 3288 & - & - & - & Yes \\
\hline & 2 & 1.09 & 3438 & - & - & - & Yes \\
\hline & 3 & 1.08 & - & 282 & - & - & - \\
\hline & 4 & 1.09 & 3343 & - & - & - & Yes \\
\hline & 5 & 1.08 & 3175 & - & - & - & Yes \\
\hline
\end{tabular}


Table 12. Ballistic results, averaged.

\begin{tabular}{lllllll}
\hline Formulation & $\begin{array}{l}\text { Bulk density } \\
\mathrm{g} / \mathrm{cm}^{3}\end{array}$ & $\begin{array}{l}\text { VOD, } \\
\mathrm{m} / \mathrm{s}\end{array}$ & $\begin{array}{l}\text { Lead block, } \\
\mathrm{cm}\end{array}$ & $\begin{array}{l}\text { Booster } \\
\text { PV15 }\end{array}$ & $\begin{array}{l}\text { Blasting } \\
\text { cap \#8 }\end{array}$ & $\begin{array}{l}\text { Explosive } \\
\text { cord NP10 }\end{array}$ \\
\hline PE1A & 1.23 & - & - & No & No & No \\
PE1B & 1.20 & 2956 & - & Yes & No & No \\
PE1C & 1.13 & 3080 & 311 & - & Yes & No \\
PE2A & 1.16 & 3350 & 276 & Yes & Yes & Yes \\
PE3A & 1.10 & 3273 & 310 & Yes & Yes & Yes \\
PE4A & 1.09 & 3409 & 280 & Yes & Yes & Yes \\
PE5A & 1.14 & 3431 & 289 & Yes & Yes & Yes \\
PE6A & 1.07 & 3400 & 328 & - & - & Yes \\
PE6B & 1.12 & 3347 & 282 & - & - & Yes \\
PE7A & 1.05 & 3248 & 304 & - & - & Yes \\
PE7B & 1.09 & 3311 & 282 & - & - & Yes \\
\hline
\end{tabular}

Therefore,

$\left[\begin{array}{c}y_{1} \\ y_{2} \\ y_{3} \\ y_{1,2} \\ y_{1,3} \\ y_{2,3} \\ y_{1,2,3}\end{array}\right]=\left[\begin{array}{ccccccc}1 & 0 & 0 & 0 & 0 & 0 & 0 \\ 0 & 1 & 0 & 0 & 0 & 0 & 0 \\ 0 & 0 & 1 & 0 & 0 & 0 & 0 \\ 1 / 2 & 1 / 2 & 0 & 1 / 4 & 0 & 0 & 0 \\ 1 / 2 & 0 & 1 / 2 & 0 & 1 / 4 & 0 & 0 \\ 0 & 1 / 2 & 1 / 2 & 0 & 0 & 1 / 4 & 0 \\ 1 / 3 & 1 / 3 & 1 / 3 & 1 / 9 & 1 / 9 & 1 / 9 & 1 / 27\end{array}\right] \cdot\left[\begin{array}{c}b_{1} \\ b_{2} \\ b_{3} \\ b_{1,2} \\ b_{1,3} \\ b_{2,3} \\ b_{1,2,3}\end{array}\right]$

or $Y_{i j}=[X] \cdot b_{i j}$, its solution being $b_{i j}=[X]^{-1}$. $Y_{i j}$, or

$\left[\begin{array}{c}b_{1} \\ b_{2} \\ b_{3} \\ b_{1,2} \\ b_{1,3} \\ b_{2,3} \\ b_{1,2,3}\end{array}\right]=\left[\begin{array}{ccccccc}1 & 0 & 0 & 0 & 0 & 0 & 0 \\ 0 & 1 & 0 & 0 & 0 & 0 & 0 \\ 0 & 0 & 1 & 0 & 0 & 0 & 0 \\ -2 & -2 & 0 & 4 & 0 & 0 & 0 \\ -2 & 0 & -2 & 0 & 4 & 0 & 0 \\ 0 & -2 & -2 & 0 & 0 & 4 & 0 \\ 3 & 3 & 3 & -12 & -12 & -12 & 27\end{array}\right] \cdot\left[\begin{array}{c}y_{1} \\ y_{2} \\ y_{3} \\ y_{1,2} \\ y_{1,3} \\ y_{2,3} \\ y_{1,2,3}\end{array}\right]$

Hence,

$$
\begin{aligned}
& \mathrm{b}_{1}=\mathrm{y}_{1} \\
& \mathrm{~b}_{2}=\mathrm{y}_{2} \\
& \mathrm{~b}_{3}=\mathrm{y}_{3} \\
& \mathrm{~b}_{1,2}=4 \cdot \mathrm{y}_{1,2}-2 \cdot\left(\mathrm{y}_{1}+\mathrm{y}_{2}\right) \\
& \mathrm{b}_{1,3}=4 \cdot \mathrm{y}_{1,3}-2 \cdot\left(\mathrm{y}_{1}+\mathrm{y}_{3}\right) \\
& \mathrm{b}_{2,3}=4 \cdot \mathrm{y}_{2,3}-2 \cdot\left(\mathrm{y}_{2}+\mathrm{y}_{3}\right) \\
& \mathrm{b}_{1,2,3}=27 \cdot \mathrm{y}_{1,2,3}-12 \cdot\left(\mathrm{y}_{1,2}+\mathrm{y}_{1,3}+\mathrm{y}_{2,3}\right)+3 \cdot\left(\mathrm{y}_{1}+\mathrm{y}_{2}+\mathrm{y}_{3}\right)
\end{aligned}
$$

Substituting in equations (1) the results observed for each formulation, the following values were obtained for the coefficients of the cubic model:

\section{Detonation Velocity $(\mathrm{m} / \mathrm{s})$ :}

$$
\begin{aligned}
& b_{1}=3018 ; b_{2}=3350 ; b_{3}=3273 ; \\
& b_{1,2}=900 ; b_{1,3}=1142 ; b_{2,3}=246 ; \\
& b_{1,2,3}=-5073 \\
& y=3018 x_{1}+3350 x_{2}+3273 x_{3}+
\end{aligned}
$$

$\underline{\text { Lead Block }\left(\mathrm{cm}^{\frac{3}{}}\right) \text { : }}$

$$
\begin{aligned}
\mathrm{b}_{1}= & 311 ; \mathrm{b}_{2}=276 ; \mathrm{b}_{3}=310 ; \\
\mathrm{b}_{1,2}= & -54 ; \mathrm{b}_{1,3}=-86 ; \mathrm{b}_{2,3}=140 \\
\mathrm{~b}_{1,2,3}= & -135 \\
\mathrm{y}= & 311 \mathrm{x}_{1}+276 \mathrm{x}_{2}+310 \mathrm{x}_{3}+ \\
& -54 \mathrm{x}_{1} \mathrm{x}_{2}-86 \mathrm{x}_{1} \mathrm{x}_{3}+140 \mathrm{x}_{2} \mathrm{x}_{3}+135 \mathrm{x}_{1} \mathrm{x}_{2} \mathrm{x}_{3}
\end{aligned}
$$

Similarly, the two equations above can be rewritten for a quadratic model, leading to:

Detonation Velocity $(\mathrm{m} / \mathrm{s})$ :

$$
\begin{aligned}
y= & 3018 x_{1}+3350 x_{2}+3273 x_{3}+ \\
& +900 x_{1} x_{2}+1142 x_{1} x_{3}+246 x_{2} x_{3}
\end{aligned}
$$

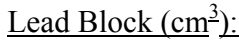

$$
\begin{aligned}
y= & 311 x_{1}+276 x_{2}+310 x_{3}+ \\
& -54 x_{1} x_{2}-86 x_{1} x_{3}+140 x_{2} x_{3}
\end{aligned}
$$

Equations (2) and (3) (or Eqs. (4) and (5)) are used to predict results of detonation velocity and lead block for a formulation specified by $\mathrm{x}_{\mathrm{i}}{ }^{\prime} \mathrm{s}$, where $\mathrm{i}=1,2,3$ stand for TNT, $\mathrm{Fe}_{2} \mathrm{O}_{3}$ and $\mathrm{S}$, respectively, being $0 \% \leq \mathrm{x}_{\mathrm{i}} \leq 100 \%$.

In order to evaluate the models it was necessary to calculate the coefficient errors. Table 13 shows these coefficients and the respective errors for both the cubic and the quadratic models.

Performing the F-test for both models led to the consent that all formulations, with the exception of PE1A,B,C, possess high probability of success when used in the field. In spite of the detonation velocities being somewhat lower than that of the standard formulation and of those obtained in phase one, there is a way to improve this situation. This would be the addition of ground ammonium and sodium nitrates during the process of grinding the slurry constituents. A few preliminary experiments with this addition were conducted and results were $15 \%$ higher in relation to those obtained with those salts as prills. 
Table 13. Coefficients and errors for the velocity of detonation and lead block for the cubic and the quadratic models.

\begin{tabular}{|c|c|c|c|c|c|c|c|c|}
\hline & \multicolumn{4}{|c|}{ Velocity of detonation } & \multicolumn{4}{|c|}{ Lead block } \\
\hline & \multicolumn{2}{|c|}{ Cubic model } & \multicolumn{2}{|c|}{ Quadratic model } & \multicolumn{2}{|c|}{ Cubic model } & \multicolumn{2}{|c|}{ Quadratic model } \\
\hline & Coeff. & Error & Coeff. & Error & Coeff. & Error & Coeff. & Error \\
\hline 1 & 3018 & \pm 43 & 3018 & \pm 48 & 311 & \pm 25 & 311 & \pm 33 \\
\hline 2 & 3350 & \pm 61 & 3350 & \pm 67 & 276 & \pm 25 & 276 & \pm 33 \\
\hline 3 & 3273 & \pm 61 & 3273 & \pm 67 & 310 & \pm 25 & 310 & \pm 33 \\
\hline 4 & 899 & \pm 285 & 900 & \pm 316 & -54 & \pm 125 & -54 & \pm 159 \\
\hline 5 & 1141 & \pm 285 & 1142 & \pm 316 & -86 & \pm 125 & -86 & \pm 159 \\
\hline 6 & 247 & \pm 243 & 248 & \pm 270 & 48 & \pm 102 & 48 & \pm 130 \\
\hline 7 & -5083 & \pm 1659 & & & 114 & \pm 699 & & \\
\hline
\end{tabular}

\section{Conclusion}

The experiments yielded positive results, far beyond the expected. The first phase, in which a reduction of $33 \%$ of the MEAN content was performed, led to a $10 \%$ raw material cost reduction. This fact allowed the rebirth of slurries in Brazil, making them competitive with fourth generation explosives.

Phase two was an attempt to a drastic reduction of the MEAN content to $17 \%$. This phase did not lead to adequate results and showed the need to use other tools, such as the Design of Experiments Technique, to proceed the investigation.

Phase three, in which the Design of Experiments Technique was used, led to a raw material cost reduction ranging from 23 to $26 \%$ relative to the cost of the standard formulation. The use of statistics displayed a confidence level of $94 \%$ for the velocity of detonation. As for the relative strength the models displayed a low confidence level, ranging from 50 to $55 \%$. This is due to the reduced number of experiments conducted with the Trauzl lead block. For every five measurements of detonation velocity, only one run was performed with the lead block.

\section{References}

Afanasenkov, A.N., Kotova, L.I., Kukiv, B.N., 2001, "Strength of commercial explosives", Combustion, Explosion and Shock Waves, Vol. 37, No. 3, pp. 349-358.
Berta, G., 1990, "Explosives: an Engineering Tool”, Italesplosivi, Milano. Cook, M.A., Farnam, H., 1960, Canadian Patent No. 597177.

Cooper, P.W., 1996, "Explosive Engineering”, Wiley-VCH, New York. Krabbendam-LaHaye, E.L.M., de Klerk, W.P.C., Kramer, R.E., 2005, "The kinetic behavior and thermal stability of commercially available explosives", Journal of Thermal Analysis and Calorimetry, Vol. 80, No. 2, pp. 495-501.

Meyer, R., 1987, "Explosives”, VCH Publishers, New York.

Pepekin, V.I., Gubin, S.A., 2007, "Heat of explosion of commercial and brisant high explosives", Combustion, Explosion and Shock Waves, Vol. 43, No. 2, pp. 212-218.

Rigas, F., Pitsinis, N., Tsimogianni, P., 1994, "The Gibbs energy minimization approach in the estimation of detonation, explosion and work production parameters of confined charges", Propellants Explosives Pyrotechnics, Vol. 19, No. 2, pp. 76-81.

Ringgenberg, O., Mathieu, J., 2004, "Commercial high explosives", Chimia, Vol. 58, No. 6, pp. 390-393.

Roux,, R.A., 1990, "CALCEXPLO”, Fábrica Presidente Vargas, Piquete, Brazil.

Roy, R.K., 2001, "Design of Experiments Using the Taguchi Approach: 16 Steps to Product and Process Improvement", John Wiley \& Sons, New York.

Urbanski, T., 1990, "Chemistry and Technology of Explosives", Pergamon Press, England.

Wharton, R.K., Formby, S.A., Merrifield, R., 2000, "Airblast TNT equivalence for a range of commercial blasting explosives", Journal of Hazardous Materials, Vol. 79, No. 1-2, pp. 31-39. 